\title{
Percepciones de estudiantes y docentes del uso que los estudiantes hacen de Internet y las redes sociales on-line, y su relación con la modalidad de estudio
}

\author{
The perception from students and teachers about their usage of \\ internet and online social networks, and its relationship with the type \\ of study
}

\author{
Rubicelia Valencia-Ortiz \\ Macmillan Education. Ciudad de México, México. \\ rubicelia.valencia@macmillaneducation.com \\ Urtza Garay \\ Universidad del País Vasco. Leioa, España. \\ urtza.garay@ehu.eus \\ Julio Cabero-Almenara \\ Universidad de Sevilla. Sevilla, España. \\ cabero@us.es
}

\begin{abstract}
Resumen
Internet y las redes sociales se han convertido en las tecnologías estrella entre los estudiantes actuales. En cambio, todavía hay pocos estudios sobre el uso y percepción que el alumnado hace de ellas. Incluso, es difícil encontrar comparaciones entre las percepciones sobre el uso que realizan los estudiantes desde el punto de vista del profesorado y del mismo alumnado. El objetivo de este trabajo es profundizar en las diferencias entre las percepciones del profesorado y los estudiantes respecto a los usos de internet y redes sociales que estos últimos realizan. La muestra está conformada por 17600 alumnos y 1498 docentes de la Ciudad de México. Se realizó un estudio exploratorio y ex post-facto, mediante el instrumento de recogida de datos "Social Media Addiction Scale-Studen Form". Entre los resultados destaca la diferencia entre la percepción de uso que presenta el alumnado y la que tiene el profesorado. Además, son los estudiantes que cursan sus estudios a distancia los que más utilizan las redes para su proceso de aprendizaje. Estos resultados sugieren la necesidad de tomar medidas educativas para intensificar el uso formativo de internet y las redes sociales entre el alumnado.
\end{abstract}

Palabras clave: Redes sociales; internet; profesorado; alumnado; percepción.

\begin{abstract}
Internet and social media have become so trend tech activity among the current students. On the other hand, there are still few studies about the usage and the perceptions students have about them. It is even harder to find some comparisons between the perception of the students and the professors in this topic. The purpose of this work is to deepen into the existent differences between the students and teachers perceptions referred to the Internet and social media usage. The sample gathered 17600 students and 1498 teachers within Mexico City. The study was made to explore and post-facto as well, using data form from "Social Media Addiction Scale-Student Form". The results emphasized the difference between the perception of usage for students and for teachers. Students who work their curricula on line, use the internet for their learning process. These results suggest the need to apply educative dictations to intensify the formative use of internet and social media in the student's environment.
\end{abstract}

Keywords: Socital media; Internet; teachers; students; perception 


\section{Introducción}

Una de las transformaciones más significativas que se ha producido en la educación durante los últimos 20 años es la incorporación de la formación virtual a las instituciones educativas, entre otros motivos porque los desarrollos tecnológicos creados a partir de las herramientas de la web 2.0, así como las modificaciones tecnológicas que se han producido en las plataformas de formación virtual, han propiciado un aumento, por una parte de la interacción entre los participantes en dichas plataformas, y por otra, de las herramientas que favorecen la comunicación sincrónica; variables que aparecen en diferentes estudios como referentes para conseguir acciones formativas a distancia virtuales de calidad (Cabero-Almenara, Arancibia y Petre, 2019; Camacho, Zapata, Menendez y Canto, 2018; Dorfsman, 2018; Gregory y Bannister, 2017; López, López y Prieto, 2018; Preste y Cabero-Almenara, 2019; Salim y Luo, 2019; Zamora, 2018).

Al mismo tiempo, esta formación virtual, que al principio se limitaba a los contextos universitarios y de formación permanente, se ha ampliado a los no universitarios, y ha adquirido una fuerte significación en los contextos latinoamericanos (Cárdenas y Anaya, 2018; Cabero-Almenara y Valencia-Ortiz, 2019; CEPAL, 2018), entre otros motivos por su vasta extensión geográfica, la falta de profesorado especializado y de calidad (Moncada, Negrete, Arias y Armijos, 2019; Moreno, 2012), independientemente de las posibilidades que este tipo de formación ofrece para el empoderamiento de determinados colectivos (Cabero-Almenara y Valencia-Ortiz, 2019).

Todo ello ha repercutido en que el imaginario social, que con anterioridad consideraba que la educación a distancia era de segunda clase o calidad, replantee su postura ante esta modalidad, pues con ella se consigue una enseñanza como mínimo igual de positiva y significativa que la formación presencial (Acevedo, Tirado y Montero, 2015; García-Aretio, 2014; Moreno, 2012). Para la calidad en la formación, lo importante no es la distancia física entre los que participan en ella, sino la distancia cognitiva entre ellos, y como se ha señalado, la incorporación de un volumen de tecnologías está eliminando la primera de estas distancias y propiciando la disminución de la segunda.

Por otra parte se debe ser consciente que la significación de esta formación virtual estará muy relacionada con diferentes aspectos: las actitudes que los estudiantes tienen hacia las tecnologías de la información y comunicación para ser aplicadas en la enseñanza (Horvat, Dobrota; Krsmanovic y Ciudanov, 2015; Sosa, Salinas y Benito, 2018; Yildirim, 2017), las percepciones y grados de satisfacción que tengan en cuanto al uso de las tecnologías (Kang y Shin, 2015), y a las competencias digitales que poseen sobre las mismas (Cabero-Almenara y Palacios-Rodríguez, 2020; George y Ramírez, 2019; Infante-Moro, Infante-Moro y Gallardo-Pérez, 2019; Paredes-Labra, Freitas y SánchezAntolín, 2019; Rodríguez-García, Raso-Sánchez y Ruiz-Palmero, 2019).

En el contexto tecnológico en el que nos encontramos, el uso de internet y las redes sociales on-line sobresalen en los estudiantes y adolescentes, respecto a las demás. Incluso éstas por su grado de abuso de utilización, han llevado a algunos autores a indicar que los alumnos pueden llegar a presentar verdaderas adicciones por el abuso que hacen de ellas (Marín y Vega-Gea, 2019; Valencia-Ortiz y Castaño, 2019).

Las posibilidades que ofrece internet a los jóvenes son bastante diversas y van desde la comunicación con pares y familiares, hasta la búsqueda de información y datos, pasando por la creación de escenarios para el ocio y la diversión (Darder, Benito y Salinas, 2015). Formas de uso que dependen de diferentes variables, como las formaciones

Percepciones de estudiantes y docentes del uso que los estudiantes hacen de Internet y su relación con la modalidad de estudio. Valencia-Ortiz, Garay, U. y Cabero-Almenara, J. Página 2 de 23 
intelectual y tecnológica que poseen los estudiantes, o el papel que la familia ejerciese en la formación de sus descendientes.

En cuanto a la aplicación de las redes sociales on-line en la formación, señalar que se están incorporando progresivamente a la enseñanza, ya que como ponen de manifiesto diferentes trabajos (García-Valcárcel, 2013; Kang y Shin, 2015), su utilización ofrece resultados significativos para la adquisición de conocimientos y competencias por los estudiantes. De todas formas, también es cierto, que algunos autores llaman la atención respecto a que su uso no es tan mayoritario como debería ser, y su incorporación se centra más en el ocio y aspectos tangenciales de la formación (Altuzarra, Galvez y González, 2018; García-Ruiz, Tirado, y Hernando, 2018; Rodríguez-Gallego, López-Martínez y Navarro-Montaño, 2019; Torrego-González y Gutiérrez-Martín, 2016).

Por otra parte, no se debe olvidar que el uso de redes sociales on-line, también está contrastado por una serie de acontecimientos, que van desde las actitudes que se tengan hacia las mismas, hasta la formación que el docente tenga para su incorporación a la enseñanza (Mayor-Buzón, García-Pérez y Rebollo-Catalán, 2019).

Diferentes han sido los estudios centrados en la problemática de la búsqueda de variables que influyan en el uso que los jóvenes hacen de internet y las redes sociales online, como la edad, género, nivel de estudio o competencias digitales (Hernández y Torrijos, 2019; Marín, Sampedro y Vega, 2017; Mayor-Buzón et al., 2019; Tejada, Castaño y Romero, 2019). Sin embargo, pocos han sido los trabajos que se centran en conocer si hay diferencias respecto a las actitudes, percepciones, formas de uso o niveles de satisfacción, donde se comparen a estudiantes que se forman o profesores que enseñan, en contextos de educación presencial y a distancia, entre los trabajos que se han desarrollado se suelen especificar diferencias en los comportamientos (Cabanillas, Luengo, y Torres, 2019). Además, pocos son los estudios que se centran en conocer si existen diferencias, respecto a las percepciones que profesores y estudiantes tienen sobre el uso de diferentes tecnologías, entre ellas internet y las redes sociales (Arancibia, Cabero-Almenara y Valdivia, 2019; Chiecher y Lorenzati, 2017; Fasli y Ozdamli, 2018).

\section{La investigación realizada}

\section{Objetivos de la investigación}

Los objetivos de esta investigación se declaran en los siguientes términos:

1) Conocer los usos que los estudiantes de nivel medio superior realizan de internet, y determinar si existen diferencias significativas en función de la modalidad presencial o a distancia;

2) Conocer la utilidad educativa que para los estudiantes tienen las Redes Sociales On-line (RSO), y determinar si existen diferencias significativas en función de la modalidad presencial o a distancia;

3) Conocer si hay diferencias significativas entre las percepciones de los docentes sobre los usos que los estudiantes realizan de internet, y analizar si hay diferencias significativas en función de que realicen su actividad profesional en las modalidades presencial o a distancia.

4) Conocer si hay diferencias significativas en la utilidad educativa que para ellos tienen las RSO, y analizar si hay las diferencias significativas en función de que realicen su actividad profesional en las modalidades presencial o a distancia

Percepciones de estudiantes y docentes del uso que los estudiantes hacen de Internet y su relación con la modalidad de estudio. Valencia-Ortiz, Garay, U. y Cabero-Almenara, J. Página 3 de 23 
5) Analizar si se dan diferencias significativas entre las percepciones que tienen los profesores y los estudiantes respecto a los usos que los estudiantes hacen de Internet.

6) Analizar si se dan diferencias significativas entre las percepciones que tienen los profesores y los estudiantes respecto a la utilidad educativa que para ellos tienen las RSO.

Para lograr estos objetivos, efectuamos un estudio exploratorio y ex post-facto (Mateo, 2004) que forma parte de un trabajo que perseguía diferentes objetivos entre ellos uno centrado en el análisis de la adicción a las RSO por los estudiantes que cursan la preparatoria en México. Las preguntas utilizadas para la presente investigación se incorporaron a escala de adicción a las redes sociales elaborada por Sahin (2018), Social Media Addiction Scale-Student Form (en adelante SMAS-SF) (Cabero-Almenara, PérezDíez y Valencia-Ortiz, 2020; Valencia-Ortiz y Castaño, 2019). La administración del instrumento fue vía Internet.

\section{La muestra de la investigación}

La muestra está compuesta por estudiantes y docentes del nivel de la preparatoria de México pertenecientes, a la Prepa en Línea SEP (Secretaría de Educación Pública de México) y al Colegio de Bachilleres en Ciudad de México. La muestra estuvo compuesta por 17600 estudiantes y 1498 docentes. El número de mujeres fue mayor tanto en estudiantes ( $\mathrm{f}=12149,69.03 \%)$ como en docentes $(\mathrm{f}=902,60.21 \%)$. La mayoría de los estudiantes tenían menos de 20 años ( $\mathrm{f}=4$ 101, 23.30\%), seguidos del grupo "entre $20 \mathrm{y}$ 25 años" ( $\mathrm{f}=2710,15.40 \%)$ y "entre 31 y 35 años" ( $\mathrm{f}=22291,13.02 \%)$.

\section{Resultados de la investigación}

La tabla 1 presenta los resultados sobre las preferencias de uso de internet y la utilidad educativa que para los estudiantes tienen las RSO. Para una correcta interpretación de las medias y desviaciones típicas obtenidas se debe tener en cuenta que la escala de contestación ofrecida en la primera pregunta referente al uso de internet era la siguiente: $0=$ Nunca 0 casi nunca, $1=$ Rara vez, $2=$ A veces, $3=$ Con frecuencia y $4=$ Siempre o casi siempre; mientras que la segunda escala iba de $0=$ nada, a 10= Muchísimo.

Tabla 1. Medias y desviaciones típicas de uso de internet: total de estudiantes, estudiantes en línea y estudiantes de forma presencial.

\begin{tabular}{|l|c|c|c|c|c|c|}
\hline \multirow{2}{*}{ Estudiantes: usos de Internet } & \multicolumn{2}{|c|}{ En línea } & \multicolumn{2}{c|}{ Presencial } & \multicolumn{2}{c|}{ Total } \\
\cline { 2 - 8 } & Media & D. tip. & Media & D. tip. & Media & D. tip. \\
\hline Redes sociales & 2.62 & 1.09 & 2.94 & 0.95 & 2.65 & 1.08 \\
\hline Mensajería instantánea & 2.42 & 1.15 & 2.76 & 0.97 & 2.45 & 1.14 \\
\hline Chats o grupos & 2.93 & 1.10 & 2.39 & 1.12 & 2.87 & 1.12 \\
\hline $\begin{array}{l}\text { Navegar libremente por diferentes } \\
\text { páginas web. }\end{array}$ & 2.61 & 0.98 & 2.23 & 0.99 & 2.57 & 0.99 \\
\hline $\begin{array}{l}\text { Buscar información que se me pide para } \\
\text { mis estudios. }\end{array}$ & 3.29 & 0.79 & 3.06 & 0.86 & 3.27 & 0.80 \\
\hline $\begin{array}{l}\text { Buscar y descargar diferentes cosas } \\
\text { (música, imágenes, documentos...). }\end{array}$ & 2.54 & 1.05 & 2.76 & 1.01 & 2.57 & 1.05 \\
\hline $\begin{array}{l}\text { Ver películas o series directamente, sin } \\
\text { descargar. }\end{array}$ & 1.80 & 1.29 & 2.15 & 1.25 & 1.84 & 1.29 \\
\hline
\end{tabular}

Percepciones de estudiantes y docentes del uso que los estudiantes hacen de Internet y su relación con la modalidad de estudio. Valencia-Ortiz, Garay, U. y Cabero-Almenara, J. Página 4 de 23 
RED. Revista de Educación a Distancia. Núm. 62 Vol. 20. Artíc. 08, 31-03-2020

DOI: http://dx.doi.org/10.6018/red.411781

\begin{tabular}{|c|c|c|c|c|c|c|}
\hline $\begin{array}{l}\text { Escuchar música o ver videos sin } \\
\text { descargar. }\end{array}$ & 2.48 & 1.17 & 2.81 & 1.07 & 2.52 & 1.17 \\
\hline Juegos en línea & 0.74 & 1.08 & 1.35 & 1.35 & 0.81 & 1.12 \\
\hline \multirow[t]{2}{*}{ Estudiantes: usos redes sociales } & \multicolumn{2}{|c|}{ En línea } & \multicolumn{2}{|c|}{ Presencial } & \multicolumn{2}{|c|}{ Total } \\
\hline & Media & D. tip. & Media & D. tip. & Media & D. tip. \\
\hline Recibir información & 7.07 & 2.59 & 7.44 & 2.06 & 7.11 & 2.54 \\
\hline Comunicarse con los amigos y familia & 7.25 & 2.62 & 8.11 & 2.03 & 7.34 & 2.58 \\
\hline Estudios y formación & 7.62 & 2.86 & 7.82 & 2.06 & 7.64 & 2.79 \\
\hline $\begin{array}{l}\text { Navegar libremente por diferentes } \\
\text { páginas web. }\end{array}$ & 3.92 & 3.13 & 6.33 & 2.74 & 4.17 & 3.18 \\
\hline
\end{tabular}

La tabla anterior permite señalar ver una serie de aspectos: las valoraciones que hacen los estudiantes, tanto presenciales como en línea, no son muy elevadas de los usos que hacen de internet, ya que pocas superan el valor de 3; hay cierta homogeneidad en el número de uso de internet y de las RSO; el uso más elevado que se da en ambos grupos de estudiantes es el de "buscar información que me pide para mis estudios", en el uso de Internet, mientras que en el de las RSO, los estudiantes "en línea" destacan "estudio y formación", y los estudiantes presenciales en "comunicarse con la familia y los amigos".

En el caso de los docentes las puntuaciones medias y desviaciones típicas alcanzadas se presentan en la tabla 2.

Tabla 2. Medias y desviaciones típicas de uso de internet: total de docentes, docentes en línea y docentes de forma presencial.

\begin{tabular}{|c|c|c|c|c|c|c|}
\hline \multirow[t]{2}{*}{ Docentes: Usos de Internet } & \multicolumn{2}{|c|}{ En línea } & \multicolumn{2}{|c|}{ Presencial } & \multicolumn{2}{|c|}{ Total } \\
\hline & Media & D. tip. & Media & D. tip. & Media & D. tip. \\
\hline Redes sociales & 3.35 & 0.72 & 3.64 & 0.60 & 3.40 & 0.71 \\
\hline Mensajería instantánea & 3.03 & 0.84 & 3.37 & 0.73 & 3.09 & 0.83 \\
\hline Chats o grupos & 3.53 & 0.66 & 3.61 & 0.65 & 3.55 & 0.66 \\
\hline $\begin{array}{l}\text { Navegar libremente por diferentes } \\
\text { páginas web. }\end{array}$ & 2.87 & 0.80 & 3.00 & 0.79 & 2.89 & 0.80 \\
\hline $\begin{array}{l}\text { Buscar información que se me pide para } \\
\text { mis estudios. }\end{array}$ & 2.73 & 0.92 & 2.52 & 0.97 & 2.69 & 0.94 \\
\hline $\begin{array}{l}\text { Buscar y descargar diferentes cosas } \\
\text { (música, imágenes, documentos...). }\end{array}$ & 2.97 & 0.79 & 3.23 & 0.68 & 3.02 & 0.78 \\
\hline $\begin{array}{l}\text { Ver películas o series directamente, sin } \\
\text { descargar. }\end{array}$ & 2.58 & 0.88 & 2.74 & 0.85 & 2.61 & 0.87 \\
\hline $\begin{array}{l}\text { Escuchar música o ver videos sin } \\
\text { descargar. }\end{array}$ & 2.96 & 0.82 & 3.12 & 0.77 & 2.99 & 0.82 \\
\hline Juegos en línea & 2.28 & 1.05 & 2.95 & 0.88 & 2.40 & 1.05 \\
\hline \multirow[t]{2}{*}{ Docentes: Usos redes sociales } & \multicolumn{2}{|c|}{ En línea } & \multicolumn{2}{|c|}{ Presencial } & \multicolumn{2}{|c|}{ Total } \\
\hline & Media & D. tip. & Media & D. tip. & Media & D. tip. \\
\hline Recibir información & 8.03 & 2.10 & 7.90 & 2.17 & 8.01 & 2.11 \\
\hline Comunicarse con los amigos y familia & 8.83 & 1.66 & 8.75 & 1.69 & 8.81 & 1.66 \\
\hline Estudios y formación & 6.81 & 2.57 & 6.07 & 2.44 & 6,67 & 2,56 \\
\hline $\begin{array}{l}\text { Navegar libremente por diferentes } \\
\text { páginas web. }\end{array}$ & 7.78 & 2.39 & 8.07 & 2.21 & 7,84 & 2,36 \\
\hline
\end{tabular}

Respecto de los docentes, lo primero que destaca es que son los de la enseñanza presencial los que consideran que sus estudiantes realizan un uso mayor de los diferentes aspectos señalados en el cuestionario de internet. Ocurre lo contrario en la pregunta formulada

Percepciones de estudiantes y docentes del uso que los estudiantes hacen de Internet y su relación con la modalidad de estudio. Valencia-Ortiz, Garay, U. y Cabero-Almenara, J. Página 5 de 23 
respecto al uso de las RSO, donde los docentes que trabajan en línea consideran que son sus alumnos los que hacen un uso mayor. En cambio, para los docentes que trabajan de forma presencial el uso mayor que hacen sus estudiantes de internet es el de las "redes sociales", mientras que los que trabajan en línea consideran que es el uso de "chats o grupos". También señalar, que ambos colectivos de docentes consideran que sus estudiantes utilizan, sobre todo, las RSO para "comunicarse con los amigos y familia". Una vez presentados los valores descriptivos de los dos colectivos y de las diversas modalidades en las cuales se desenvolvían, se pasará a analizar las siguientes hipótesis:

a) H0 (hipótesis nula): No existen diferencias significativas en los usos identificados de internet, según la modalidad de los estudiantes, ya sea en línea o presencial, con un riesgo alfa de equivocarnos del 0.05 o menor;

b) H1 (hipótesis alternativa): Sí existen diferencias significativas en los usos identificados de internet, según la modalidad de los estudiantes, ya sea en línea o presencial, con un riesgo alfa de equivocarnos del 0.05 o menor.

Para su contraste, y para las posteriores que se presentarán, el estadístico a utilizar será la t de Student para muestras independientes, pero antes aplicaremos la prueba de Levene para analizar la igualdad de las varianzas, y en función de la puntuación obtenida, determinar el valor t de Student, que se utilizará para la aceptación o rechazo de la H0. En el caso de alcanzar diferencias significativas, es decir rechazar la H0, se obtendrá el tamaño del efecto mediante la g de Hedges (Ellis, 2010), para conocer la potencia de tales diferencias. En la tabla $n^{\circ} 3$, se presentan los resultados alcanzados con la prueba de Levene y la t de Student.

Tabla 3. Test de Levene y t de Student, en función de que los alumnos estudiaran la preparatoria mexicana en línea o de forma presencial.

\begin{tabular}{|c|c|c|c|c|c|c|}
\hline & \multicolumn{2}{|c|}{ Test de Levene } & \multicolumn{3}{|c|}{ Para la igualdad de medias } \\
\hline & & $\mathbf{F}$ & Sig. & $\mathbf{t}$ & gl & Sig. \\
\hline \multirow[t]{2}{*}{ Redes sociales } & $\begin{array}{l}\text { Se asumen } \\
\text { varianzas iguales }\end{array}$ & 150.419 & 0.000 & -12.09 & 17598 & .000 \\
\hline & $\begin{array}{l}\text { No se asumen } \\
\text { varianzas iguales }\end{array}$ & & & -13.53 & 2462.778 & $\begin{array}{l}.000 \\
(* *)\end{array}$ \\
\hline \multirow[t]{2}{*}{$\begin{array}{l}\text { Mensajería } \\
\text { instantánea }\end{array}$} & $\begin{array}{l}\text { Se asumen } \\
\text { varianzas iguales }\end{array}$ & 155.737 & 0.000 & -12.26 & 17598 & .000 \\
\hline & $\begin{array}{l}\text { No se asumen } \\
\text { varianzas iguales }\end{array}$ & & & -14.06 & 2506.016 & $\begin{array}{l}.000 \\
(* *)\end{array}$ \\
\hline \multirow[t]{2}{*}{ Chats o grupos } & $\begin{array}{l}\text { Se asumen } \\
\text { varianzas iguales }\end{array}$ & 50.566 & 0.000 & 19.933 & 17598 & .000 \\
\hline & $\begin{array}{l}\text { No se asumen } \\
\text { varianzas iguales }\end{array}$ & & & 19.687 & 2288.879 & $\begin{array}{l}.000 \\
(* *) \\
\end{array}$ \\
\hline \multirow{2}{*}{$\begin{array}{l}\text { Navegar } \\
\text { libremente por } \\
\text { diferentes } \\
\text { páginas web. }\end{array}$} & $\begin{array}{l}\text { Se asumen } \\
\text { varianzas iguales }\end{array}$ & 1.154 & 0.283 & 15.978 & 17598 & .000 \\
\hline & $\begin{array}{l}\text { No se asumen } \\
\text { varianzas iguales }\end{array}$ & & & 15.852 & 2294.175 & $\begin{array}{l}.000 \\
(* *)\end{array}$ \\
\hline \multirow{2}{*}{$\begin{array}{l}\text { Buscar } \\
\text { información que } \\
\text { me piden para } \\
\text { mis estudios. }\end{array}$} & $\begin{array}{l}\text { Se asumen } \\
\text { varianzas iguales }\end{array}$ & 6.782 & 0.009 & 11.829 & 17598 & .000 \\
\hline & $\begin{array}{l}\text { No se asumen } \\
\text { varianzas iguales }\end{array}$ & & & 11.057 & 2229.152 & $\begin{array}{l}.000 \\
(* *)\end{array}$ \\
\hline $\begin{array}{l}\text { Buscar y } \\
\text { descargar }\end{array}$ & $\begin{array}{l}\text { Se asumen } \\
\text { varianzas iguales }\end{array}$ & 18.288 & 0.000 & -8.359 & 17598 & .000 \\
\hline
\end{tabular}

Percepciones de estudiantes y docentes del uso que los estudiantes hacen de Internet y su relación con la modalidad de estudio. Valencia-Ortiz, Garay, U. y Cabero-Almenara, J. Página 6 de 23 


\begin{tabular}{|c|c|c|c|c|c|c|}
\hline $\begin{array}{l}\text { diferentes cosas } \\
\text { (música. } \\
\text { imágenes. } \\
\text { documentos...). }\end{array}$ & $\begin{array}{l}\text { No se asumen } \\
\text { varianzas iguales }\end{array}$ & & & -8.631 & 2344.098 & $\begin{array}{l}.000 \\
(* *)\end{array}$ \\
\hline \multirow{2}{*}{$\begin{array}{l}\text { Ver películas o } \\
\text { series } \\
\text { directamente. sin } \\
\text { descargar. }\end{array}$} & $\begin{array}{l}\text { Se asumen } \\
\text { varianzas iguales }\end{array}$ & 6.481 & 0.011 & -11.18 & 17598 & .000 \\
\hline & $\begin{array}{l}\text { No se asumen } \\
\text { varianzas iguales }\end{array}$ & & & -11.42 & 2330.033 & $\begin{array}{l}.000 \\
(* *)\end{array}$ \\
\hline \multirow{2}{*}{$\begin{array}{l}\text { Escuchar música } \\
\text { o ver videos sin } \\
\text { descargar. }\end{array}$} & $\begin{array}{l}\text { Se asumen } \\
\text { varianzas iguales }\end{array}$ & 76.436 & 0.000 & -11.58 & 17598 & .000 \\
\hline & $\begin{array}{l}\text { No se asumen } \\
\text { varianzas iguales }\end{array}$ & & & -12.46 & 2401.339 & $\begin{array}{l}.000 \\
(* *)\end{array}$ \\
\hline \multirow[t]{2}{*}{ Juegos en línea } & $\begin{array}{l}\text { Se asumen } \\
\text { varianzas iguales }\end{array}$ & 353.629 & 0.000 & -22.36 & 17598 & .000 \\
\hline & $\begin{array}{l}\text { No se asumen } \\
\text { varianzas iguales }\end{array}$ & & & -18.67 & 2130.762 & $\begin{array}{l}.000 \\
(* *)\end{array}$ \\
\hline
\end{tabular}

* significativo a $\mathrm{p} \leq .05$

** significativo a $\mathrm{p} \leq .01$

Nota: en negritas valor t de Student en función de asumir o no, varianzas iguales.

En todos los casos los valores t obtenidos permiten rechazar la $\mathrm{H} 0$ con un riesgo alfa de equivocarnos de $\mathrm{p} \leq .01$; luego, podemos concluir que las percepciones que los estudiantes tienen de los diferentes usos que hacen de internet, son diferentes según cursan sus estudios de la preparatoria mexicana, en línea o de forma presencial. Los usos son superiores en los alumnos que estudian en línea, en los siguientes casos:

- Chats o grupos.

- Navegar libremente por diferentes páginas web.

- Buscar información que me piden para mis estudios.

Por su parte, los niveles más significativos de uso en los alumnos presenciales son los siguientes:

- Redes sociales.

- Mensajería instantánea.

- Buscar y descargar diferentes cosas (música, imágenes, documentos).

- Ver películas o series directamente, sin descargar.

- Escuchar música o ver videos sin descargar.

- Juegos en línea.

La tabla 4 presenta el tamaño del efecto de los diferentes resultados significativos obtenidos en distintos usos de internet.

Percepciones de estudiantes y docentes del uso que los estudiantes hacen de Internet y su relación con la modalidad de estudio. Valencia-Ortiz, Garay, U. y Cabero-Almenara, J. Página 7 de 23 
Tabla 4. Tamaño del efecto

\begin{tabular}{|l|c|}
\hline \multicolumn{1}{|c|}{ Ítem } & $\begin{array}{c}\text { Tamaño del } \\
\text { efecto }\end{array}$ \\
\hline Redes sociales. & 0.297483 \\
\hline Mensajería instantánea. & 0.300066 \\
\hline Chats o grupos. & 0.487894 \\
\hline Navegar libremente por diferentes páginas web. & 0.385765 \\
\hline Buscar información que me piden para mis estudios. & 0.289804 \\
\hline $\begin{array}{l}\text { Buscar y descargar diferentes cosas (música, imágenes, } \\
\text { documentos). }\end{array}$ & 0.209391 \\
\hline Ver películas o series directamente, sin descargar. & 0.273123 \\
\hline Escuchar música o ver videos, sin descargar. & 0.284332 \\
\hline Juegos en línea & 0.550306 \\
\hline
\end{tabular}

Siguiendo a Cohen (1988), se puede señalar que salvo en el caso del uso de "Juegos en línea", cuyo tamaño del efecto se puede considerar de intermedio, en el resto de los ítems los efectos del tamaño han sido pequeños.

Para analizar si variaban las percepciones entre los docentes de acuerdo a su modalidad, en línea o de forma presencial, respecto a los usos que los estudiantes hacen de internet, aplicamos la prueba de Levene y la t de Student, con las que se validó si se aceptaba o no la $\mathrm{H} 0$, que refiere a la no existencia de diferencias significativas entre ambos colectivos con un riesgo alfa de equivocarnos de 0.05 . Los valores obtenidos se muestran en la tabla 5 .

Tabla 5. Test de Levene y $t$ de Student para el análisis de las diferencias significativas en los profesores en función de su modalidad, en línea o de forma presencial.

\begin{tabular}{|c|c|c|c|c|c|c|}
\hline & \multicolumn{2}{|c|}{ Prueba de Levene } & \multicolumn{3}{|c|}{ para la igualdad de medias } \\
\hline & & $\mathbf{F}$ & Sig. & $\mathbf{t}$ & gl & Sig. \\
\hline \multirow[t]{2}{*}{ Redes sociales. } & $\begin{array}{l}\text { Se asumen } \\
\text { varianzas iguales }\end{array}$ & 20.383 & 0.000 & -6.218 & 1496 & .000 \\
\hline & $\begin{array}{l}\text { No se asumen } \\
\text { varianzas iguales }\end{array}$ & & & -6.966 & 471.171 & $\begin{array}{l}.000 \\
(* *)\end{array}$ \\
\hline \multirow[t]{2}{*}{$\begin{array}{l}\text { Mensajería } \\
\text { instantánea. }\end{array}$} & $\begin{array}{l}\text { Se asumen } \\
\text { varianzas iguales }\end{array}$ & 0.768 & 0.381 & -6.272 & 1496 & $\begin{array}{l}.000 \\
(* *)\end{array}$ \\
\hline & $\begin{array}{l}\text { No se asumen } \\
\text { varianzas iguales }\end{array}$ & & & -6.894 & 458.762 & .000 \\
\hline \multirow[t]{2}{*}{ Chats o grupos. } & $\begin{array}{l}\text { Se asumen } \\
\text { varianzas iguales }\end{array}$ & 2.810 & 0.094 & -1.614 & 1496 & .107 \\
\hline & $\begin{array}{l}\text { No se asumen } \\
\text { varianzas iguales }\end{array}$ & & & -1.629 & 412.740 & .104 \\
\hline \multirow{2}{*}{$\begin{array}{l}\text { Navegar } \\
\text { libremente por } \\
\text { diferentes } \\
\text { páginas web. }\end{array}$} & $\begin{array}{l}\text { Se asumen } \\
\text { varianzas iguales }\end{array}$ & 2.659 & 0.103 & -2.521 & 1496 & $.012(* *)$ \\
\hline & $\begin{array}{l}\text { No se asumen } \\
\text { varianzas iguales }\end{array}$ & & & -2.540 & 412.015 & .011 \\
\hline \multirow{2}{*}{$\begin{array}{l}\text { Buscar } \\
\text { información que } \\
\text { se me pide para } \\
\text { mis estudios. }\end{array}$} & $\begin{array}{l}\text { Se asumen } \\
\text { varianzas iguales }\end{array}$ & 1.348 & 0.246 & 3.424 & 1496 & $.001(* *)$ \\
\hline & $\begin{array}{l}\text { No se asumen } \\
\text { varianzas iguales }\end{array}$ & & & 3.308 & 393.988 & .001 \\
\hline
\end{tabular}

Percepciones de estudiantes y docentes del uso que los estudiantes hacen de Internet y su relación con la modalidad de estudio. Valencia-Ortiz, Garay, U. y Cabero-Almenara, J. Página 8 de 23 


\begin{tabular}{|c|c|c|c|c|c|c|}
\hline \multirow{2}{*}{$\begin{array}{l}\text { Buscar y } \\
\text { descargar } \\
\text { diferentes cosas } \\
\text { (música. } \\
\text { imágenes. } \\
\text { documentos...). }\end{array}$} & $\begin{array}{l}\text { Se asumen } \\
\text { varianzas iguales }\end{array}$ & 0.002 & 0.967 & -5.067 & 1496 & $\begin{array}{l}.000 \\
(* *) \\
\end{array}$ \\
\hline & $\begin{array}{l}\text { No se asumen } \\
\text { varianzas iguales }\end{array}$ & & & -5.584 & 460.394 & .000 \\
\hline \multirow{2}{*}{$\begin{array}{l}\text { Ver películas o } \\
\text { series } \\
\text { directamente. } \\
\text { sin descargar. }\end{array}$} & $\begin{array}{l}\text { Se asumen } \\
\text { varianzas iguales }\end{array}$ & 5.044 & 0.025 & -2.801 & 1496 & .005 \\
\hline & $\begin{array}{l}\text { No se asumen } \\
\text { varianzas iguales }\end{array}$ & & & -2.864 & 418.961 & $\begin{array}{l}.004 \\
(* *)\end{array}$ \\
\hline \multirow{2}{*}{$\begin{array}{l}\text { Escuchar música } \\
\text { o ver videos sin } \\
\text { descargar. }\end{array}$} & $\begin{array}{l}\text { Se asumen } \\
\text { varianzas iguales }\end{array}$ & 0.069 & 0.793 & -3.003 & 1496 & $.003(* *)$ \\
\hline & $\begin{array}{l}\text { No se asumen } \\
\text { varianzas iguales }\end{array}$ & & & -3.148 & 431.548 & .002 \\
\hline \multirow[t]{2}{*}{ Juegos en línea } & $\begin{array}{l}\text { Se asumen } \\
\text { varianzas iguales }\end{array}$ & 45.186 & $\begin{array}{r}0.000 \\
(* *) \\
\end{array}$ & -9.987 & 1496 & .000 \\
\hline & $\begin{array}{l}\text { No se asumen } \\
\text { varianzas iguales }\end{array}$ & & & -11.14 & 468.359 & $\begin{array}{r}.000 \\
(* *) \\
\end{array}$ \\
\hline
\end{tabular}

* significativo a $\mathrm{p} \leq .05$

** significativo a $\mathrm{p} \leq .01$

Nota: en negritas valor t de Student en función de asumir o no, varianzas iguales.

Hay que señalar que en todos los casos se rechazan las $\mathrm{H} 0$ formuladas a un nivel de significación de $\mathrm{p} \leq .05$, salvo en el referido a la utilización del "Chats o grupos". Por lo tanto, se concluye que la percepción del uso que hacen de internet los estudiantes varía en función de que los docentes realicen su actividad profesional de la enseñanza en línea o de manera presencial. Al respecto, salvo en el caso de "Buscar información que se me pide para mis estudios", donde son los profesores a distancia los que consideran que los estudiantes hacen un mayor uso de este rubro; el resto son profesores presenciales quienes consideran que sus estudiantes lo hacen en mayor grado.

Por lo que se refiere al tamaño del efecto, alcanzado en aquellos casos en los que se había rechazado la $\mathrm{H} 0$, las puntuaciones obtenidas se presentan en la tabla 6.

Tabla 6. Tamaño del efecto.

\begin{tabular}{|l|c|}
\hline \multicolumn{1}{|c|}{ Ítem } & $\begin{array}{c}\text { Tamaño del } \\
\text { efecto }\end{array}$ \\
\hline RSO (Facebook, Instagram, Snapchat, Twitter, LinkedIn, etc.). & 0.413156 \\
\hline $\begin{array}{l}\text { Mensajería instantánea (Facebook, Skype, Gtalk, Windows Live, } \\
\text { Yahoo, Messenger, etc.). }\end{array}$ & 0.413334 \\
\hline Navegar libremente por diferentes páginas web. & 0.221443 \\
\hline Buscar información que me piden para mis estudios. & 0.351736 \\
\hline $\begin{array}{l}\text { Buscar y descargar diferentes cosas (música, imágenes, } \\
\text { documentos...). }\end{array}$ & 0.185898 \\
\hline Ver películas o series directamente, sin descargar. & 0.201112 \\
\hline Escuchar música o ver videos sin descargar. & 0.284332 \\
\hline Juegos en línea & 0.700056 \\
\hline
\end{tabular}

Como se observa, los tamaños del efecto identificado pueden considerarse como "pequeños" de acuerdo con Cohen (1988), salvo en el caso de "juegos en línea", cuyo tamaño del efecto es considerable.

Percepciones de estudiantes y docentes del uso que los estudiantes hacen de Internet y su relación con la modalidad de estudio. Valencia-Ortiz, Garay, U. y Cabero-Almenara, J. Página 9 de 23 
Por lo que se refiere a si se dieron diferencias entre docentes y estudiantes en función de que desarrollaran su actividad profesional o estudiaran en línea. Los estadísticos obtenidos se presentan en la tabla 7.

Tabla 7. Test de Levene y $t$ de student para el análisis de las diferencias significativas en los profesores en función de trabajaran en la preparatoria en línea.

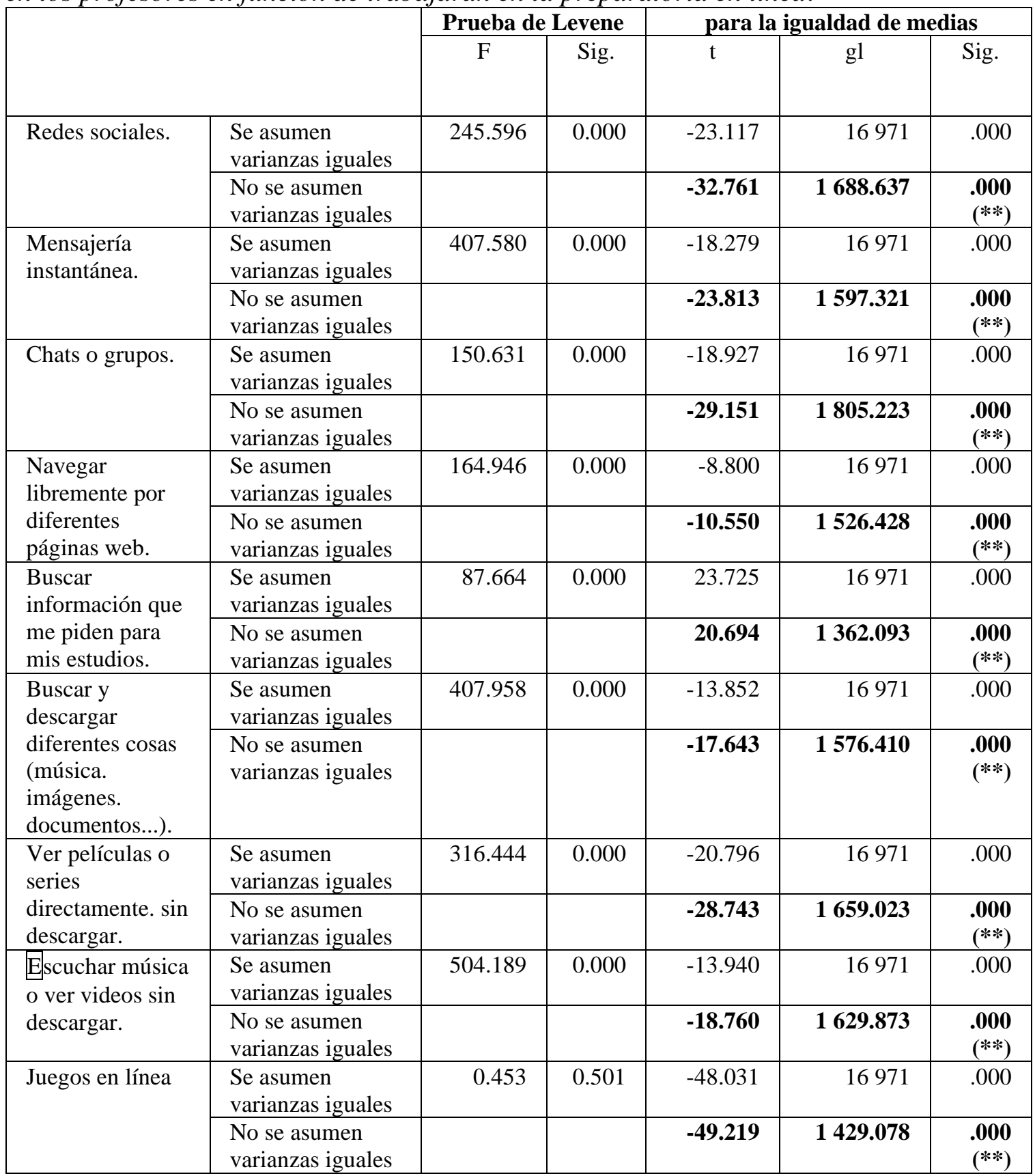

* significativo a $\mathrm{p} \leq 05$.

** significativo a $\mathrm{p} \leq .01$.

Nota: en negritas valor $\mathrm{t}$ de Student en función de asumir o no, varianzas iguales.

Los valores encontrados permiten rechazar todas las diferentes $\mathrm{H} 0$ formuladas, a un nivel de significación de $\mathrm{p} \leq 0.01$, por lo que se concluye que hay diferencias de percepciones

Percepciones de estudiantes y docentes del uso que los estudiantes hacen de Internet y su relación con la modalidad de estudio. Valencia-Ortiz, Garay, U. y Cabero-Almenara, J. Página 10 de 23 
entre los profesores y los estudiantes de la modalidad en línea, sobre los usos que los alumnos hacen de internet. En todos los casos, salvo en "Navegar libremente por diferentes páginas web", son los docentes quienes creen que son más utilizados por los estudiantes.

Respecto al tamaño del efecto, los valores obtenidos se presentan en la tabla.

Tabla 8. Tamaño del efecto.

\begin{tabular}{|l|r|}
\hline \multicolumn{1}{|c|}{ Ítem } & $\begin{array}{c}\text { Tamaño del } \\
\text { efecto }\end{array}$ \\
\hline Redes sociales. & 0.297483 \\
\hline Mensajería instantánea. & 0.300066 \\
\hline Chats o grupos. & 0.487894 \\
\hline Navegar libremente por diferentes páginas web. & 0.385765 \\
\hline Buscar información que me piden para mis estudios. & 0.289804 \\
\hline Buscar y descargar diferentes cosas (música, imágenes, documentos...). & 0.209391 \\
\hline Ver películas o series directamente, sin descargar. & 0.273123 \\
\hline Escuchar música o ver videos sin descargar. & 0.284332 \\
\hline Juegos en línea & 0.550306 \\
\hline
\end{tabular}

De nuevo los resultados encontrados sugieren por lo general, pequeños tamaños del efecto, salvo en lo referido a los "Juegos en línea" y la utilización de los "chats o grupos" que podemos considerarlos como moderado.

A continuación, se pasará a realizar los mismos análisis, pero en este caso con los docentes y estudiantes de modalidad presencial. Los valores t de Student alcanzados se presentan en la tabla 9.

Tabla 9. Test de Levene y $t$ de Student para el análisis de las diferencias significativas en los profesores de preparatoria modalidad presencial.

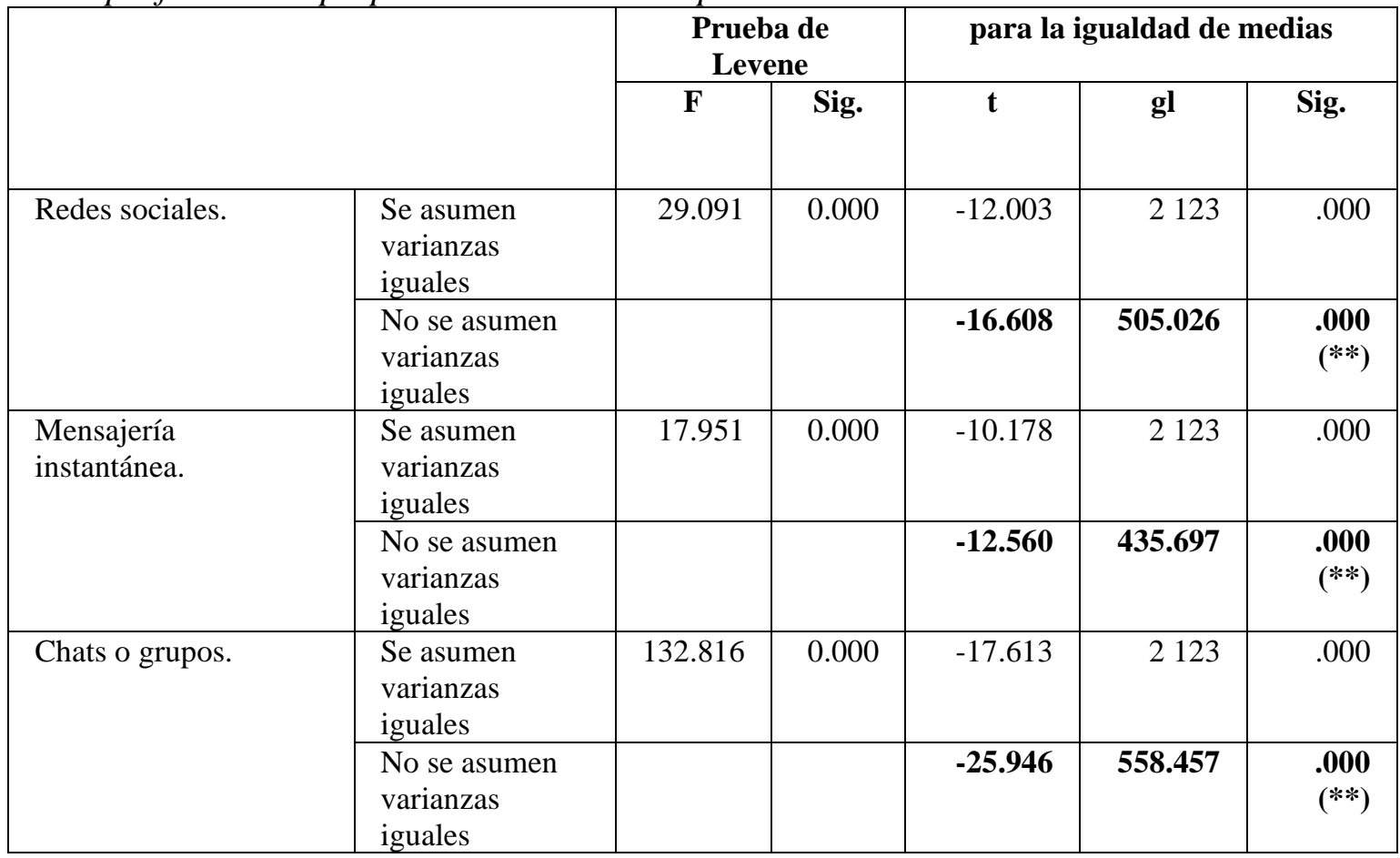

Percepciones de estudiantes y docentes del uso que los estudiantes hacen de Internet y su relación con la modalidad de estudio. Valencia-Ortiz, Garay, U. y Cabero-Almenara, J. Página 11 de 23 


\begin{tabular}{|c|c|c|c|c|c|c|}
\hline \multirow[t]{2}{*}{$\begin{array}{l}\text { Navegar libremente } \\
\text { por diferentes páginas } \\
\text { web. }\end{array}$} & $\begin{array}{l}\text { Se asumen } \\
\text { varianzas } \\
\text { iguales }\end{array}$ & 44.141 & 0.000 & -12.375 & 2123 & .000 \\
\hline & $\begin{array}{l}\text { No se asumen } \\
\text { varianzas } \\
\text { iguales }\end{array}$ & & & -14.703 & 418.417 & $\begin{array}{l}.000 \\
(* *)\end{array}$ \\
\hline \multirow[t]{2}{*}{$\begin{array}{l}\text { Buscar información } \\
\text { que me piden para mis } \\
\text { estudios. }\end{array}$} & $\begin{array}{l}\text { Se asumen } \\
\text { varianzas } \\
\text { iguales }\end{array}$ & 26.128 & 0.000 & 9.648 & 2123 & .000 \\
\hline & $\begin{array}{l}\text { No se asumen } \\
\text { varianzas } \\
\text { iguales }\end{array}$ & & & 8.770 & 341.385 & $\begin{array}{l}.000 \\
(* *)\end{array}$ \\
\hline \multirow{2}{*}{$\begin{array}{l}\text { Buscar y descargar } \\
\text { diferentes cosas } \\
\text { (música. imágenes. } \\
\text { documentos...). }\end{array}$} & $\begin{array}{l}\text { Se asumen } \\
\text { varianzas } \\
\text { iguales }\end{array}$ & 59.715 & 0.000 & -7.502 & 2123 & .000 \\
\hline & $\begin{array}{l}\text { No se asumen } \\
\text { varianzas } \\
\text { iguales }\end{array}$ & & & -10.006 & 479.488 & $\begin{array}{l}.000 \\
(* *)\end{array}$ \\
\hline \multirow[t]{2}{*}{$\begin{array}{l}\text { Ver películas o series } \\
\text { directamente. sin } \\
\text { descargar. }\end{array}$} & $\begin{array}{l}\text { Se asumen } \\
\text { varianzas } \\
\text { iguales }\end{array}$ & 79.269 & 0.000 & -7.561 & 2123 & .000 \\
\hline & $\begin{array}{l}\text { No se asumen } \\
\text { varianzas } \\
\text { iguales }\end{array}$ & & & -10.038 & 476.433 & $\begin{array}{l}.000 \\
(* *)\end{array}$ \\
\hline \multirow[t]{2}{*}{$\begin{array}{l}\text { Escuchar música o ver } \\
\text { videos sin descargar. }\end{array}$} & $\begin{array}{l}\text { Se asumen } \\
\text { varianzas } \\
\text { iguales }\end{array}$ & 52.338 & 0.000 & -4.622 & 2123 & .000 \\
\hline & $\begin{array}{l}\text { No se asumen } \\
\text { varianzas } \\
\text { iguales }\end{array}$ & & & -5.892 & 452.380 & $\begin{array}{l}.000 \\
(* *)\end{array}$ \\
\hline \multirow[t]{2}{*}{ Juegos en línea } & $\begin{array}{l}\text { Se asumen } \\
\text { varianzas } \\
\text { iguales }\end{array}$ & 154.772 & 0.000 & -19.030 & 2123 & .000 \\
\hline & $\begin{array}{l}\text { No se asumen } \\
\text { varianzas } \\
\text { iguales }\end{array}$ & & & -25.984 & 495.331 & $\begin{array}{l}.000 \\
(* *)\end{array}$ \\
\hline
\end{tabular}

* significativo a $\mathrm{p} \leq .05$.

** significativo a $\mathrm{p} \leq .01$.

Nota: en negritas valor t de Student en función de asumir o no, varianzas iguales.

Los valores obtenidos permiten rechazar en todos los casos las $\mathrm{H} 0$ formuladas, a un nivel de significación de $\mathrm{p} \leq .01$ en todos los casos. Se concluye que hay diferencias de percepciones entre los profesores y los estudiantes de la modalidad presencial. En todos los casos los docentes indican que los alumnos hacen un mayor uso, salvo en el de "Buscar información que se me pide para mis estudios".

Por lo que se refiere a los valores alcanzados respecto al tamaño del efecto en los casos que se han rechazado la $\mathrm{H} 0$, se presentan en la tabla 10.

Percepciones de estudiantes y docentes del uso que los estudiantes hacen de Internet y su relación con la modalidad de estudio. Valencia-Ortiz, Garay, U. y Cabero-Almenara, J. Página 12 de 23 
Tabla 10. Tamaño del efecto.

\begin{tabular}{|l|r|}
\hline \multicolumn{1}{|c|}{ Ítem } & $\begin{array}{c}\text { Tamaño del } \\
\text { efecto }\end{array}$ \\
\hline Redes sociales. & 0.771079 \\
\hline Mensajería instantánea. & 0.655762 \\
\hline Chats o grupos. & 1.137475 \\
\hline Navegar libremente por diferentes páginas web. & 0.979644 \\
\hline Buscar información que me piden para mis estudios. & 0.619134 \\
\hline Buscar y descargar diferentes cosas (música, imágenes, documentos...). & 0.481414 \\
\hline Ver películas o series directamente, sin descargar. & 0.489127 \\
\hline Escuchar música o ver videos sin descargar. & 0.299873 \\
\hline Juegos en línea & 1.228618 \\
\hline
\end{tabular}

Las puntuaciones nos permiten señalar grandes efectos del tamaño en las diferencias encontradas en los ítems: altos en "Redes sociales", "Mensajería instantánea", "Chats o grupos", "Navegar libremente por diferentes páginas web" y "Juegos en línea"; moderados en "Buscar información que me piden para mis estudios", y bajos en "Buscar y descargar diferentes cosas (música, imágenes, documentos...)", "Ver películas o series directamente, sin descargar" y "Escuchar música o ver videos sin descargar".

Para analizar si existían diferencias significativas entre el colectivo de docentes y estudiantes de forma global, los valores t de Student alcanzados se presentan en la tabla 11.

Tabla 11. Test de Levene y $t$ de student para el análisis de las diferencias significativas en los profesores en función de trabajaran en la preparatoria de forma presencial.

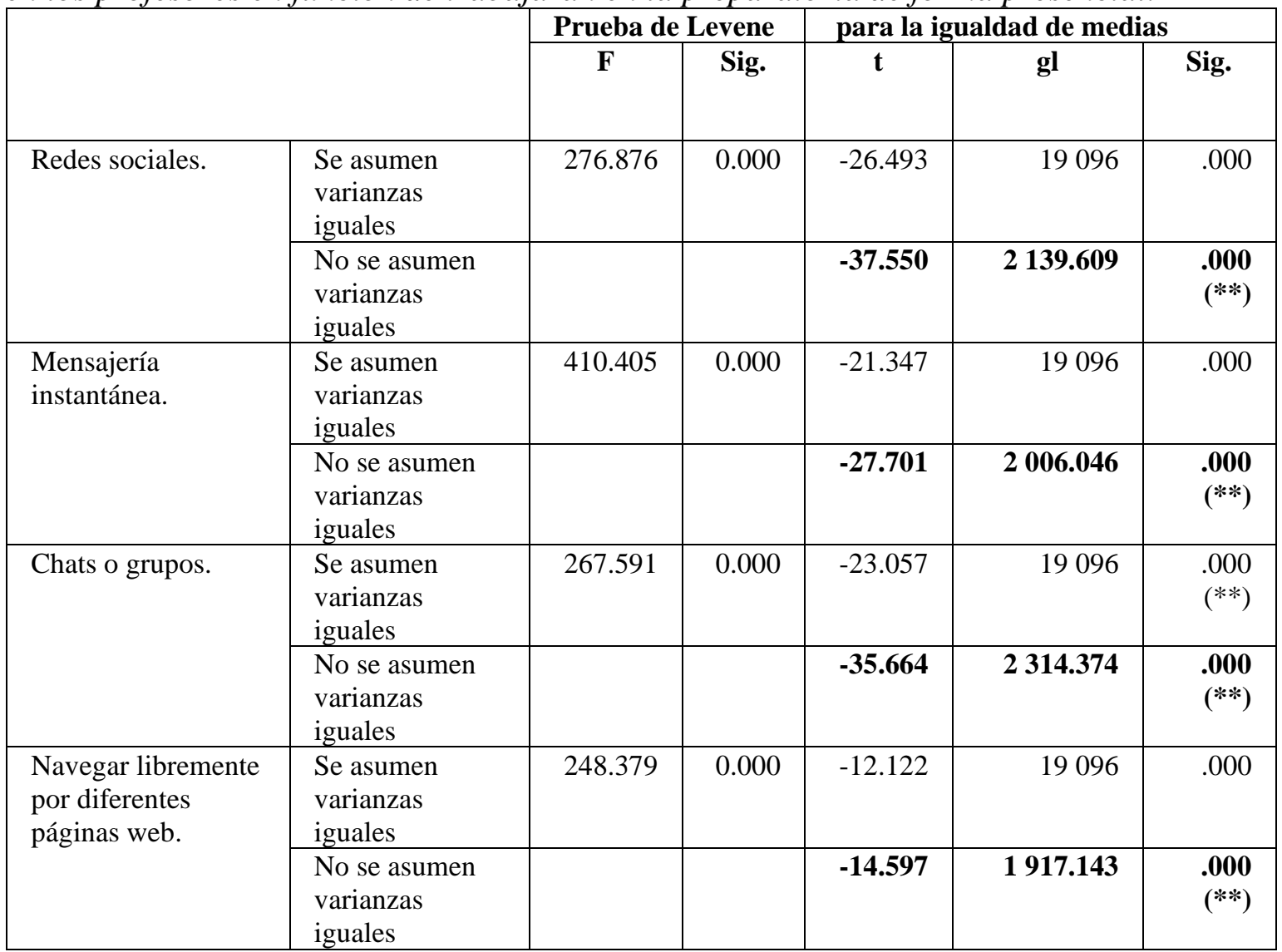

Percepciones de estudiantes y docentes del uso que los estudiantes hacen de Internet y su relación con la modalidad de estudio. Valencia-Ortiz, Garay, U. y Cabero-Almenara, J. Página 13 de 23 


\begin{tabular}{|c|c|c|c|c|c|c|}
\hline \multirow[t]{2}{*}{$\begin{array}{l}\text { Buscar información } \\
\text { que se me pide para } \\
\text { mis estudios. }\end{array}$} & $\begin{array}{l}\text { Se asumen } \\
\text { varianzas } \\
\text { iguales }\end{array}$ & 116.129 & 0.000 & 26.477 & 19096 & .000 \\
\hline & $\begin{array}{l}\text { No se asumen } \\
\text { varianzas } \\
\text { iguales }\end{array}$ & & & 23.134 & 1687.015 & $\begin{array}{l}.000 \\
(* *)\end{array}$ \\
\hline \multirow{2}{*}{$\begin{array}{l}\text { Buscar y descargar } \\
\text { diferentes cosas } \\
\text { (música. imágenes. } \\
\text { documentos...). }\end{array}$} & $\begin{array}{l}\text { Se asumen } \\
\text { varianzas } \\
\text { iguales }\end{array}$ & 532.478 & 0.000 & -16.264 & 19096 & .000 \\
\hline & $\begin{array}{l}\text { No se asumen } \\
\text { varianzas } \\
\text { iguales }\end{array}$ & & & -20.888 & 1992.561 & $\begin{array}{l}.000 \\
(* *)\end{array}$ \\
\hline \multirow[t]{2}{*}{$\begin{array}{l}\text { Ver películas o } \\
\text { series directamente. } \\
\text { sin descargar. }\end{array}$} & $\begin{array}{l}\text { Se asumen } \\
\text { varianzas } \\
\text { iguales }\end{array}$ & 380.024 & 0.000 & -22.765 & 19096 & .000 \\
\hline & $\begin{array}{l}\text { No se asumen } \\
\text { varianzas } \\
\text { iguales }\end{array}$ & & & -31.422 & 2095.593 & $\begin{array}{l}.000 \\
(* *)\end{array}$ \\
\hline \multirow[t]{2}{*}{$\begin{array}{l}\text { Escuchar música o } \\
\text { ver videos sin } \\
\text { descargar. }\end{array}$} & $\begin{array}{l}\text { Se asumen } \\
\text { varianzas } \\
\text { iguales }\end{array}$ & 657.343 & 0.000 & -15.337 & 19096 & .000 \\
\hline & $\begin{array}{l}\text { No se asumen } \\
\text { varianzas } \\
\text { iguales }\end{array}$ & & & -20.627 & 2055.952 & $\begin{array}{l}.000 \\
(* *)\end{array}$ \\
\hline \multirow[t]{2}{*}{ Juegos en línea } & $\begin{array}{l}\text { Se asumen } \\
\text { varianzas } \\
\text { iguales }\end{array}$ & .215 & 0.642 & -52.898 & 19096 & $\begin{array}{r}.000 \\
(* *)\end{array}$ \\
\hline & $\begin{array}{l}\text { No se asumen } \\
\text { varianzas } \\
\text { iguales }\end{array}$ & & & -56.024 & 1801.814 & .000 \\
\hline
\end{tabular}

* significativo a $\mathrm{p} \leq .05$.

$* *=$ significativo a $\mathrm{p} \leq .01$.

Nota: en negritas valor t de Student en función de asumir o no, varianzas iguales.

Hay que señalar que en todos los casos rechazamos las $\mathrm{H} 0$ formuladas a un nivel de significación de $\mathrm{p} \leq .01$. Por lo tanto, podemos concluir que la percepción del uso que hacen de internet los estudiantes varía de la percepción que tienen los docentes. Salvo en el caso de "Buscar información que se me pide para mis estudios", donde son los estudiantes los que consideran que hacen un uso mayor en este rubro; en el resto, los docentes consideran que sus estudiantes lo hacen en mayor grado.

Respecto al tamaño del efecto, las puntuaciones alcanzadas las presentamos en la tabla 12.

Tabla 12. Tamaño del efecto.

\begin{tabular}{|l|c|}
\hline \multicolumn{1}{|c|}{ Ítem } & $\begin{array}{c}\text { Tamaño del } \\
\text { efecto }\end{array}$ \\
\hline Redes sociales. & 0.710472 \\
\hline Mensajería instantánea. & 0.572911 \\
\hline Chats o grupos. & 0.623922 \\
\hline Navegar libremente por diferentes páginas web. & 0.326889 \\
\hline Buscar información que me piden para mis estudios. & 0.717228 \\
\hline Buscar y descargar diferentes cosas (música, imágenes, documentos...). & 0.435117 \\
\hline Ver películas o series directamente, sin descargar. & 0.611825 \\
\hline Escuchar música o ver videos sin descargar. & 0.107298 \\
\hline Juegos en línea & 1.421705 \\
\hline
\end{tabular}

Percepciones de estudiantes y docentes del uso que los estudiantes hacen de Internet y su relación con la modalidad de estudio. Valencia-Ortiz, Garay, U. y Cabero-Almenara, J. Página 14 de 23 
Las puntuaciones permiten señalar grandes efectos del tamaño en el ítem "Juegos en línea"; intermedios o moderados en: "Redes sociales", "Mensajería instantánea", "Chats o grupos" y "Buscar información que se me pide para mis estudios", y bajos en "Buscar y descargar diferentes cosas (música, imágenes, documentos...)", "Ver películas o series directamente, sin descargar", "Escuchar música o ver videos sin descargar"” y "Navegar libremente por diferentes páginas web".

Realizados estos análisis, se pasará a analizar las siguientes hipótesis:

a) Hipótesis nula (H0): No existen diferencias significativas entre la utilidad que señalan los estudiantes que cursan preparatoria que hacen de las RSO de acuerdo con su modalidad, sea en línea o de forma presencial, con un riesgo alfa de equivocarnos del 0.05 .

b) Hipótesis alternativa (H1): Sí existen diferencias significativas entre la utilidad que señalan los estudiantes que cursan preparatoria que hacen de las RSO de acuerdo con su modalidad, en línea o de forma presencial, con un riesgo alfa de equivocarnos del 0.05 .

Con el objeto de contrastar las hipótesis formuladas, aplicamos el test de Levene y el estadístico t de Student, alcanzando los valores que presentamos en la tabla 13.

Tabla 13. Estadístico de Levene y $t$ de student para existencia de diferencias significativas entre los estudiantes presenciales y en línea respecto a los usos que realizaban de las $R S O$.

\begin{tabular}{|c|c|c|c|c|c|c|}
\hline & \multicolumn{2}{|c|}{ Prueba de Levene } & \multicolumn{3}{|c|}{ para la igualdad de medias } \\
\hline & & $\mathbf{F}$ & Sig. & $\mathbf{t}$ & gl & Sig. \\
\hline \multirow[t]{2}{*}{$\begin{array}{l}\text { Recibir } \\
\text { información }\end{array}$} & $\begin{array}{l}\text { Se asumen } \\
\text { varianzas iguales }\end{array}$ & 118.590 & 0.000 & -5.941 & 17598 & .000 \\
\hline & $\begin{array}{l}\text { No se asumen } \\
\text { varianzas iguales }\end{array}$ & & & -7.115 & 2588.468 & $\begin{array}{l}.000 \\
(* *) \\
\end{array}$ \\
\hline \multirow{2}{*}{$\begin{array}{l}\text { Comunicarse con } \\
\text { los amigos y } \\
\text { familia }\end{array}$} & $\begin{array}{l}\text { Se asumen } \\
\text { varianzas iguales }\end{array}$ & 226.744 & 0.000 & -13.720 & 17598 & .000 \\
\hline & $\begin{array}{l}\text { No se asumen } \\
\text { varianzas iguales }\end{array}$ & & & -16.739 & 2627.431 & $\begin{array}{l}.000 \\
(* *) \\
\end{array}$ \\
\hline \multirow[t]{2}{*}{$\begin{array}{l}\text { Estudios y } \\
\text { formación }\end{array}$} & $\begin{array}{l}\text { Se asumen } \\
\text { varianzas iguales }\end{array}$ & 254.288 & 0.000 & -2.889 & 17598 & .004 \\
\hline & $\begin{array}{l}\text { No se asumen } \\
\text { varianzas iguales }\end{array}$ & & & -3.728 & 2760.594 & $\begin{array}{l}.000 \\
(* *)\end{array}$ \\
\hline \multirow[t]{2}{*}{ Conocer personas } & $\begin{array}{l}\text { Se asumen } \\
\text { varianzas iguales }\end{array}$ & 53.519 & 0.000 & -31.764 & 17598 & .000 \\
\hline & $\begin{array}{l}\text { No se asumen } \\
\text { varianzas iguales }\end{array}$ & & & -35.309 & 2452.270 & $\begin{array}{l}.000 \\
(* *) \\
\end{array}$ \\
\hline
\end{tabular}

* significativo a $\mathrm{p} \leq .05$.

** significativo a $\mathrm{p} \leq .01$.

Nota: en negritas valor t de Student en función de asumir o no, varianzas iguales.

Como se puede observar existen diferencias significativas a $p \leq 0.01$, y se concluye que el uso que hacen los estudiantes de las redes sociales es diferente en función de que cursen sus estudios de la preparatoria en línea o de forma presencial. En todos los casos, las puntuaciones de los estudiantes que cursan la preparatoria de forma presencial eran

Percepciones de estudiantes y docentes del uso que los estudiantes hacen de Internet y su relación con la modalidad de estudio. Valencia-Ortiz, Garay, U. y Cabero-Almenara, J. Página 15 de 23 
superiores a los que la cursaban en línea. Luego, en este caso, rechazamos todas las hipótesis nulas formuladas.

Con el objetivo de conocer el tamaño del efecto de las diferencias, aplicamos de nuevo el valor "g", que fueron para los cuatro casos donde nos encontramos diferencias significativas de 0.14564 ("Recibir información"), 0.335716 ("Comunicarse con los amigos y familia"), 0.071714 ("Estudios y formación") y de 0.779915 ("Conocer personas"). Valores que, salvo en el caso del uso para "Conocer personas", pueden considerarse pequeños, mientras que el citado puede considerarse de grande.

En cuanto a si existían diferencias significativas entre las percepciones de los docentes, según su modalidad, sobre el uso que los estudiantes hacían de las RSO, los valores $\mathrm{t}$ alcanzados para rechazar o aceptar la $\mathrm{H} 0$ se presentan en la tabla 14.

Tabla 14. Estadístico de Levene y $t$ de Student para la existencia de diferencias significativas entre los profesores presenciales y en línea respecto a los usos de los alumnos y las RSO.

\begin{tabular}{|l|l|c|r|r|r|r|}
\hline \multirow{2}{*}{} & \multicolumn{2}{|c|}{$\begin{array}{c}\text { Prueba de } \\
\text { Levene }\end{array}$} & \multicolumn{2}{c|}{ para la igualdad de medias } \\
\cline { 3 - 7 } & F & Sig. & $\mathbf{t}$ & gl & Sig. \\
\hline $\begin{array}{l}\text { Recibir } \\
\text { información }\end{array}$ & $\begin{array}{l}\text { Se asumen } \\
\text { varianzas iguales }\end{array}$ & 2.812 & 0.094 & $\mathbf{0 . 9 5 4}$ & $\mathbf{1 4 9 6}$ & $\mathbf{0 . 3 4 0}$ \\
\cline { 2 - 7 } & $\begin{array}{l}\text { No se asumen } \\
\text { varianzas iguales }\end{array}$ & & & 0.932 & 398.752 & 0.352 \\
\hline $\begin{array}{l}\text { Comunicarse con } \\
\text { los amigos y } \\
\text { familia }\end{array}$ & $\begin{array}{l}\text { Se asumen } \\
\text { varianzas iguales }\end{array}$ & 0.100 & 0.752 & $\mathbf{0 . 6 9 0}$ & $\mathbf{1 4 9 6}$ & $\mathbf{0 . 4 9 0}$ \\
\cline { 2 - 7 } & $\begin{array}{l}\text { No se asumen } \\
\text { varianzas iguales }\end{array}$ & & & 0.682 & 403.586 & 0.495 \\
\hline $\begin{array}{l}\text { Estudios y } \\
\text { formación }\end{array}$ & $\begin{array}{l}\text { Se asumen } \\
\text { varianzas iguales }\end{array}$ & 0.060 & 0.807 & $\mathbf{4 . 4 0 0}$ & $\mathbf{1 4 9 6}$ & $\mathbf{0 . 0 0 0}(* *)$ \\
\cline { 2 - 7 } & $\begin{array}{l}\text { No se asumen } \\
\text { varianzas iguales }\end{array}$ & & & 4.544 & 423.729 & 0.000 \\
\hline Conocer personas & $\begin{array}{l}\text { Se asumen } \\
\text { varianzas iguales }\end{array}$ & 4.505 & 0.034 & -1.784 & 1496 & 0.075 \\
\cline { 2 - 7 } & $\begin{array}{l}\text { No se asumen } \\
\text { varianzas iguales }\end{array}$ & & & $\mathbf{- 1 . 8 7 7}$ & $\mathbf{4 3 3 . 5 4 4}$ & $\mathbf{0 . 0 6 1}$ \\
\hline
\end{tabular}

* significativo a $\mathrm{p} \leq 0.05$

** significativo a $\mathrm{p} \leq 0.01$

Nota: en negritas valor t de Student en función de asumir o no, varianzas iguales.

En este caso, mayoritariamente no se rechazan la $\mathrm{H} 0$ a un nivel de significación de $\mathrm{p} \leq$ 0.05. En concreto, los profesores que imparten docencia en línea y de manera presencial piensan que los usos que hacen los alumnos de las redes son iguales para "recibir información", "comunicarse con los amigos y la familia" y "conocer personas". Los profesores que enseñan en línea consideran que sus alumnos utilizan más las redes para "Estudios y la formación. Analizado el tamaño del efecto para la única opción donde se habían obtenido diferencias significativas, "Estudio y formación", el valor encontrado fue de 0.290315 . Valor que podemos considerar que tiene pequeño efecto.

En último lugar, presentaremos si han existido diferencias entre la globalidad de los estudiantes y los docentes respecto al uso que realizaban de las RSO. En la tabla 15 se

Percepciones de estudiantes y docentes del uso que los estudiantes hacen de Internet y su relación con la modalidad de estudio. Valencia-Ortiz, Garay, U. y Cabero-Almenara, J. Página 16 de 23 
presentan los valores t de Student obtenidos para aceptar o rechazar la H0, en este caso no se exponen los resultados teniendo en cuenta la forma en la que estudiaban los alumnos ya que los resultados son similares a los globales.

Tabla 15. $t$ de Student para diferencias significativas entre las percepciones del uso que hacen de las redes los estudiantes y los profesores.

\begin{tabular}{|c|c|c|c|c|c|c|}
\hline & \multicolumn{2}{|c|}{ Prueba de Levene } & \multicolumn{3}{|c|}{ para la igualdad de medias } \\
\hline & & $\mathbf{F}$ & Sig. & $\mathbf{t}$ & gl & Sig. \\
\hline \multirow[t]{2}{*}{ Recibir información } & $\begin{array}{l}\text { Se asumen } \\
\text { varianzas iguales }\end{array}$ & 118.949 & 0.000 & $\begin{array}{r}- \\
13.278\end{array}$ & 19096 & .000 \\
\hline & $\begin{array}{l}\text { No se asumen } \\
\text { varianzas iguales }\end{array}$ & & & $\begin{array}{r}- \\
15.528\end{array}$ & 1887.327 & $\begin{array}{l}.000 \\
(* *)\end{array}$ \\
\hline \multirow[t]{2}{*}{$\begin{array}{l}\text { Comunicarse con los } \\
\text { amigos y familia }\end{array}$} & $\begin{array}{l}\text { Se asumen } \\
\text { varianzas iguales }\end{array}$ & 456.978 & 0.000 & $\begin{array}{r}- \\
21.756\end{array}$ & 19096 & .000 \\
\hline & $\begin{array}{l}\text { No se asumen } \\
\text { varianzas iguales }\end{array}$ & & & 31.239 & 2162.525 & $\begin{array}{l}.000 \\
(* *)\end{array}$ \\
\hline \multirow[t]{2}{*}{ Estudios y formación } & $\begin{array}{l}\text { Se asumen } \\
\text { varianzas iguales }\end{array}$ & 9.770 & 0.002 & 12.955 & 19096 & .000 \\
\hline & $\begin{array}{l}\text { No se asumen } \\
\text { varianzas iguales }\end{array}$ & & & 13.908 & 1812.183 & $\begin{array}{l}.000 \\
(* *)\end{array}$ \\
\hline \multirow[t]{2}{*}{ Conocer personas } & $\begin{array}{l}\text { Se asumen } \\
\text { varianzas iguales }\end{array}$ & 320.249 & 0.000 & $\begin{array}{r}- \\
43.656\end{array}$ & 19096 & .000 \\
\hline & $\begin{array}{l}\text { No se asumen } \\
\text { varianzas iguales }\end{array}$ & & & $\begin{array}{r}- \\
55.952\end{array}$ & 1989.938 & $\begin{array}{l}.000 \\
(* *)\end{array}$ \\
\hline
\end{tabular}

* significativo a $\mathrm{p} \leq 0.05$.

** significativo a $\mathrm{p} \leq 0.01$.

Los valores obtenidos permiten rechazar las $\mathrm{H} 0$ formuladas por la carencia de diferencias significativas en cuanto al nivel de uso que hacen los estudiantes de las RSO, entre los alumnos y los profesores, con un riesgo alfa de equivocarnos del 0.01. En consecuencia, los profesores y los estudiantes tienen percepciones diferentes respecto a la utilidad que tienen las RSO; en todos los casos los alumnos piensan que las usan más para los aspectos señalados. En este caso los valores del efecto encontrados fueron los siguientes: 0.385109 ("Recibir información"), 0.584392 ("Comunicarse con los amigos y familia"), 0.349925 ("Estudios y formación") y de 1.176 (Conocer personas). Valores que pueden considerarse de pequeños "Recibir información" y "Estudios y formación", intermedios "Recibir información" y elevados "Conocer personas".

\section{Conclusiones y discusión}

Las conclusiones a las que llegamos con base en la investigación realizada son las siguientes: se han encontrado diferencias significativas entre la percepción que los docentes y estudiantes tienen respecto a los usos que hacen los últimos de internet y de las RSO. Por lo general, los docentes piensan que los estudiantes hacen un elevado uso de diferentes aspectos señalados de Internet y las RSO que los propios alumnos. Encontrándose elevadas diferencias en aspectos altamente significativos, como la utilización de internet para los juegos en línea y las redes sociales para comunicarse con los amigos y la familia. Ello nos lleva a señalar la necesitan de establecer planes de

Percepciones de estudiantes y docentes del uso que los estudiantes hacen de Internet y su relación con la modalidad de estudio. Valencia-Ortiz, Garay, U. y Cabero-Almenara, J. Página 17 de 23 
formación en competencia digital de los estudiantes, que nos llevan a que posean no solo competencias instrumentales para el manejo de las tecnologías, sino, como se sugiere desde diferentes marcos competenciales como el DigComp 2.1 (Carretero, Vuorikari y Punie, 2017; González, Román y Prendes, 2018; Kluzer, Pujol Priego, Carretero, Punie, Vuorikari y Cabrera, 2018), para la utilización creativa y productiva de las tecnologías.

Se han encontrado también diferencias significativas entre las percepciones de los usos que los estudiantes hacen de Internet y de las redes sociales, en función de que cursaran los estudios de la preparatoria mexicana, de forma presencial o en línea. Ello sugiere, que si la apropiación de las tecnologías por parte de los estudiantes depende de variables como la edad, el género, o el nivel de estudio (Hernández y Torrijos, 2019; Marín, Sampedro y Vega, 2017; Mayor-Buzón et al., 2019; Tejada, Castaño y Romero, 2019); también si el estudiante estudia de forma presencial o en línea, determina creencias y usos específicos de las tecnologías.

Los estudiantes de la modalidad en línea suelen hacer un uso más elevado de internet que sus compañeros presenciales, esto pudiera explicarse por los aspectos relacionados con las exigencias que plantea esta modalidad de estudios, como son la búsqueda de información y establecer contactos en grupos. Por el contrario, en el resto de los usos, sobresalen los estudiantes de la modalidad presencial. Resultan llamativas las diferencias que se han dado en el uso de "juegos en línea", donde las diferencias significativas encontradas son bastante amplias. Ello denotaría, por una parte, una recepción de internet como una herramienta centrada en la educación y no en el ocio para los estudiantes que estudian en línea.

Los usos elevados que muestran los estudiantes, tanto los que estudian de forma presencial como los que lo hacen de forma virtual, en las RSO, nos lleva a proponer la necesidad de establecer una formación específica para una correcta utilización de las mismas, que evite que dicha utilización aumente y con su abuso, pueda convertirse en adicción, con consecuencias negativas para los estudiantes en aspectos de salud, síndrome de abstinencia, rendimiento académico (Fernández y otros, 2015; Gairín y Mercader, 2018).

Se han encontrado diferencias marcadas entre las percepciones que los estudiantes tienen sobre los usos que hacen de internet y las percepciones que muestran sus profesores. En todos los casos, salvo en "buscar información que se me pide para mis estudios", los profesores piensan que los estudiantes hacen un uso más elevado de estas herramientas. La diferencia más amplia que destaca es el uso que hacen de los "juegos en línea", entre otras. Tales diferencias se han mantenido tanto en la percepción de los profesores en línea como en los presenciales, aunque los tamaños de dichas diferencias son menores entre el alumnado que cursan sus estudios en línea.

Estas diferencias también se han encontrado en los usos que hacen de las redes sociales, que son diferentes en función de si estudian en línea o de forma presencial. Los alumnos que realizan sus estudios de forma presencial indican que las usan con más frecuencias que los que están en una modalidad en línea. Las mayores diferencias se han establecido en la categoría "Conocer personas." Ello creemos que podría resolverse con la incorporación de las RSO por parte de los docentes a tareas educativas, que les lleve a percibir a los estudiantes, a percibir que son instrumentos que pueden utilizarse para diferentes acciones educativas, como por ejemplo el trabajo colaborativo.

Por lo general, los docentes que trabajan en la preparatoria, bien sea en línea o de forma presencial, no perciben que hay diferencias en los usos que los estudiantes tienen respecto a las RSO. Solo se han observado diferencias en el uso referido a "Conocer personas",

Percepciones de estudiantes y docentes del uso que los estudiantes hacen de Internet y su relación con la modalidad de estudio. Valencia-Ortiz, Garay, U. y Cabero-Almenara, J. Página 18 de 23 
donde los profesores que trabajan de forma presencial perciben que sus alumnos lo hacen más ampliamente que los profesores que trabajan en la preparatoria en línea. Otras de las diferencias destacables entre las percepciones de los profesores y estudiantes, es que los primeros piensan que los alumnos hacen más uso de las RSO para las diferentes propuestas indicadas que los propios estudiantes.

El trabajo presenta una serie de limitaciones que debemos asumir y de las cuales las principales son: que estamos trabajando con percepciones, y estas, como es conocido, nos hacen trabajar con las visiones de los entrevistados, es decir en un plano más abstracto; en el caso del grupo que trabaja y estudia de forma presencial se ha centrado en un único punto, y por último que el instrumento utilizado no ha sido muy amplio, como consecuencia de llevar a cabo un estudio exploratorio.

Tales limitaciones nos indican al mismo tiempo una serie de líneas futuras de investigación, entre las que podemos señalar: construir y validar un instrumento más potente y profundo para conocer las diferencias en función de estudiar o trabajar en presencialidad o virtualidad, realizar estudios en profundidad mediante investigaciones de carácter cualitativo, y replicar la investigación con una muestra más amplia de alumnos que cursan la preparatoria de forma presencial.

Puede ser también interesante trabajar con el modelo TAM ("Technology Acceptance Model") formulado originalmente por Davis (1989), que sugiere que las creencias, actitudes o predisposiciones que se tengan sobre las tecnologías repercutirán sobre su posible utilización. Predisposiciones que vendrán conformadas dos por variables: la utilidad percibida ("Perceived usefulness") y la facilidad de uso percibida ("Perceived ease of use"). Modelo que se ha utilizado para el análisis de diversas tecnologías, que van desde las emergentes como la "realidad aumentada" (Martínez y Fernández, 2018) o la aplicación de la formación virtual del m-learning (Yáñez-Luna y Arias-Oliva, 2018).

Los resultados aportados por este estudio sugieren la necesidad de tomar una serie de medidas educativas, entre las que destaca priorizar el desarrollo de formaciones específicas en el ámbito de internet y redes sociales, para así implementar su uso formativo, sobre todo en aquellos casos en los que se cursen estudios presenciales.

Presentación del artículo: 27 de enero, 2019

Fecha de aprobación: 13 de marzo de 2020

Fecha de publicación: 31 de marzo de 2020

Valencia-Ortiz, R., Garay, U. y Cabero-Almenara, J. (2020). Percepciones de estudiantes y docentes del uso que los estudiantes hacen de Internet y su relación con la modalidad de estudio. RED. Revista Educación a Distancia, 20(62). DOI: http://dx.doi.org/10.6018/red.411781

\section{Financiación}

Esta investigación no ha recibido ninguna subvención específica de los organismos de financiación en los sectores públicos, comerciales o sin fines de lucro.

Percepciones de estudiantes y docentes del uso que los estudiantes hacen de Internet y su relación con la modalidad de estudio. Valencia-Ortiz, Garay, U. y Cabero-Almenara, J. Página 19 de 23 


\section{Referencias}

Acevedo, D., Tirado, D. F. y Montero, P. M. (2015). Perfil de Aprendizaje y Rendimiento Académico en una Asignatura de Química en Modalidad a Distancia y Presencial en dos Programas de Ingeniería. Formación Universitaria, 8(6), 39-46. doi: 10.4067/S0718-50062015000600006.

Altuzarra, A., Gálvez, C. y González, A. (2018). Explorando el potencial de los dispositivos electrónicos y de las redes sociales en el proceso de enseñanzaaprendizaje de los universitarios. EDUTEC, Revista Electrónica de Tecnología Educativa, 64. 18-40. doi: 10.21556/edutec.2018.64.1031

Arancibia, M.L., Cabero-Almenara, J. y Valdivia, I.M. (2019). Estudio comparativo entre docentes y estudiantes sobre aceptación y uso de tecnologías con fines educativos en el contexto chileno. Apertura, 11(1), 104-119. doi: 10.32870/Ap.v11n1.1440

Cabanillas, J.L, Luengo, R. y Torres, Carvalho, J. L. (2019). Diferencias de actitud hacia las TIC en la formación profesional en entornos presenciales y virtuales (Plan @ vanza). Pixel-Bit. Revista de Medios y Educación, 55, 37-55. doi: 10.12795/pixelbit.2019.i55.03.

Cabero, J., Pérez-Díez, J. L. y Valencia-Ortiz, R. (2020). Escala para medir la adicción de estudiantes a las redes sociales. Convergencia. Revista de Ciencias Sociales, 27, 1-29. doi: 10.29101/crcs.v27i83.11834

Cabero-Almenara, J. y Palacios-Rodríguez, A. (2020). Marco Europeo de Competencia Digital Docente «DigCompEdu» y cuestionario «DigCompEdu Check-In». EDMETIC, Revista de Educación Mediática y TIC, 9(1), 213-234. doi: 10.21071/edmetic.v9i1.12462

Cabero-Almenara, J. y Valencia-Ortiz, R. (2019). TIC para la inclusión: una mirada desde Latinoamérica. Aula Abierta, 48(2), 139-146. doi: 10.17811/rifie.48.2.2019.139146

Cabero-Almenara, J., Arancibia, M. L. y Petre, A. del (2019). Technical and Didactic Knowledge of the Moodle LMS in Higher Education. Beyond Functional Use. Journal of New Approaches in Educational Research, 8(1), 25-33. doi: 10.7821/naer.2019.1.327

Camacho, P. E., Zapata, A., Menendez, V. M y Canto, P. J. (2018). Análisis del desempeño del profesorado universitario en el uso de MOODLE a través de técnicas de minería de datos: propuestas de necesidades formativas. RED. Revista de Educación a Distancia, 58 (10), 1-41. doi: 10.6018/red/58/10http://www.um.es/ead/red/58/camacho_et_al.pdf

Cárdenas, M.C. y Anaya, C. (2018). @ prende.mx: la política pública de educación digital de México para enfrentar los retos del siglo XXI. En P. Rivera-Vargas, J. Muñoz, R. Morales y S. Butendiech (eds.), Políticas Públicas para la Equidad Social (pp. 31-44). Santiago de Chile: USACH.

Carretero, S., Vuorikari, R., \& Punie, Y. (2017). DigComp 2.1: The Digital Competence Framework for Citizens With eight proficiency levels and examples of use. Luxembourg: Publication Office of the European Union. https://doi.org/10.2760/38842

CEPAL (2018). Agenda 2030 y los Objetivos de Desarrollo Sostenible: Una oportunidad para América Latina y el Caribe. Santiago de Chile: CEPAL.

Percepciones de estudiantes y docentes del uso que los estudiantes hacen de Internet y su relación con la modalidad de estudio. Valencia-Ortiz, Garay, U. y Cabero-Almenara, J. Página 20 de 23 
Chiecher, A. y Lorenzat, K. (2017). Estudiantes y tecnologías. Una visión desde la 'lente' de docentes universitarios. RIED. Revista Iberoamericana de Educación a Distancia, 20(1), 261-282. doi: 10.5944/ried.20.1.16334

Cohen. J. (1988). Statistical power analysis for the behavioral sciences. New York: Erlbaum.

Darder, A., Benito, B. y Salinas, J. (2015). Internet en los procesos de enseñanzaaprendizaje. En J. Cabero y J. Barroso (coords.), Nuevos retos en tecnología educativa (pp. 131-150). Madrid: Síntesis.

Davis, F. (1989), Perceived usefulness, perceived ease of use, and user acceptance of information technology. MIS Quarterly, 13(3), 319-340. DOI: 10.2307/249008.

Dorfsman, M. (2018). El educador en línea: más allá de la digitalidad. RED. Revista de Educación a Distancia, 56(9), doi: 10.6018/red/56/9

Ellis, P. (2010). The Essential Guide to Effect Sizes: Statistical Power, Meta-Analysis, and the Interpretation of Research Results. Cambridge: Cambridge University Press.

Fasli, E. y Ozdamli, F. (2018). Teacher Candidates' Opinions Regarding Instructional and Safe Use of Social Networks and Internet Addiction Risk Levels. TEM Journal, 7(2), 405-410. doi: 10.18421/TEM72

Fernández, T., y otros (2015). Uso problemático de internet en estudiantes universitarios: factores asociados y diferencias de género. Adicciones, 27(4), 265-275.

Gairin, J. y Mercader, C. (2018). Usos y abusos de las TIC en los adolescentes. Revista de Investigación Educativa, 36(1), 125-140.

García-Aretio, L. (2014). Bases, mediaciones y futuro de la educación a distancia. Madrid: Síntesis.

García-Ruiz, R., Tirado, R. y Hernando, A. (2018). Redes sociales y estudiantes: motivos de uso y gratificaciones. Evidencias para el aprendizaje. Aula Abierta, 47(3), 291298. doi: 10.17811/rifie.47.3.2018.291-298

García-Valcárcel, A. (2013). Las implicaciones educativas de las redes sociales en I. Aguaded y J. Cabero (coords.). Tecnologías y medios para la educación en la esociedad (pp. 91-116). Madrid: Alianza.

George, C. y Ramíez, A. (2019). Competencias investigativas y saberes digitales de estudiantes de posgrado en la modalidad virtual. Certiuni Journal, 5, 65-78.

González Calatayud, V., Román García, M., \& Prendes Espinosa, M. P. (2018). Formación en competencias digitales para estudiantes universitarios basada en el modelo DigComp. Edutec. Revista Electrónica De Tecnología Educativa, (65), 115 (391). https://doi.org/10.21556/edutec.2018.65.1119.

Gregory, S. y Bannister, M. (2017). Digital learner presence and online teaching tools: higher cognitive requirements of online learners for effective learning. Technology Enhanced Learning, 12(18), 1-17. doi: 10.1186/s41039-017-0059-3.

Hernández, J. P. y Torrijos, P. (2019). Percepción del profesorado sobre la integración de las Tecnologías de la Información y la Comunicación (TIC) en las modalidades docentes. Influencia del género y la edad. EDMETIC, Revista de Educación Mediática y TIC, 8(1), 128-146 doi: 10.21071/edmetic.v8i1.10537

Horvat, A., Dobrota, M., Krsmanovic, M. y Ciudanov, M. (2015). Student perception of Moodle learning management system: a satisfaction and significance. Analysis. Interactive Learning Environments, 23(4), 515-527. doi: 10.1080/10494820.2013.788033

Percepciones de estudiantes y docentes del uso que los estudiantes hacen de Internet y su relación con la modalidad de estudio. Valencia-Ortiz, Garay, U. y Cabero-Almenara, J. Página 21 de 23 
Infante-Moro, A., Infante-Moro, J. C., Gallardo-Pérez, J. (2019). The Importance of ICTs for Students as a Competence for their Future Professional Performance: the Case of the Faculty of Business Studies and Tourism of the University of Huelva. Journal of New Approaches in Educational Research, 8(2), 201-213. doi: 10.7821/naer.2019.7.434

Jaggars, Sh. y Xu, D. (2016). How do online course design features influence student performance? Computers \& Education, 95, 270-284. doi: 10.1016/j.compedu.2016.01.014

Kang, M. y Shin, W. (2015). An Empirical Investigation of Student Acceptance of Synchronous E-Learning in an Online University. Journal of Educational Computing Research, 52(4) 475-495.

Kluzer, S., Pujol Priego, L., Carretero, S., Punie, Y., Vuorikari, R., y Cabrera, M. (2018). DigComp into action, get inspired make it happen a user guide to the European Digital Competence framework. Seville: JRC. https://doi.org/10.2760/112945

List, A., Brante, E. W. y Klee, H. L. (2020). A framework of pre-service teachers' conceptions about digital literacy: Comparing the United States and Sweden. Computers and Education, 148. https://doi.org/10.1016/j.compedu.2019.103788

López, L., Lopez, B. y Prieto, E. (2018). Tendencias innovadoras en la formación on-line. La oferta web de postgrados e-learning y blended learning en España. Pixel-Bit. Revista de Medios y Educación, 53, 1-15. doi: 10.12795/pixelbit.2018

Marín, V. y Vega-Gea, E. (2019). Determination of problematic use of social networks by university students. RIED. Revista Iberoamericana de Educación a Distancia, 22(2), (version preprint). doi: 10.5944/ried.22.2.23289

Marín, V., Sampedro, B. y Vega, E. (2017). Percepciones de los estudiantes universitarios sobre las plataformas de formación. Estudio de caso. RIED. Revista Iberoamericana de Educación a Distancia, 20(1), 283-303.

Martínez, S. y Fernández, B. (2018). Objetos de realidad aumentada: percepciones del alumnado de pedagogía. Pixel-Bit. Revista de Medios y Educación, 53, 207-220. doi: http://dx.doi.org/10.12795/pixelbit.2018.i53.14

Mateo, J. (2004). La investigación ex post-facto. En R. Bisquerra (coord.). Metodología de la investigación educativa (pp. 195-230). Madrid: la Muralla.

Mayor-Buzón, V., García-Pérez, R. y Rebollo-Catalán, A. (2019). Explorando factores predictores de la competencia digital en las redes sociales virtuales. Pixel-Bit. Revista de Medios y Educación, 56, 51-69. doi: 10.12795/pixelbit.2019.i56.03

Moncada, L., Negrete, F., Arias, M. y Armijos, R. (2019). Análisis de la triada: integración académica, permanencia y dispersión geográfica. RIED. Revista Iberoamericana de Educación a Distancia, 22(1), 271-288. doi: 10.5944/ried.22.1.22001

Moreno, M. (coord.) (2012). Veinte visiones de la educación a distancia. Guadalajara: Universidad de Guadalajara.

Paredes-Labra, J., Freitas, A. y Sánchez-Antolín, P. (2019). De la iniciación al manejo tolerado de tecnologías. La competencia digital de los estudiantes madrileños antes de la educación secundaria. RED. Revista de Educación a Distancia, 19(61). doi: $10.6018 / \mathrm{red} / 61 / 03$

Preste, A. del y Cabero-Almenara, J. (2019). Las plataformas de formación virtual: algunas variables que determinan su utilización. Apertura, 11(2), 138-153. doi: 10.32870/Ap.v11n2.152

Percepciones de estudiantes y docentes del uso que los estudiantes hacen de Internet y su relación con la modalidad de estudio. Valencia-Ortiz, Garay, U. y Cabero-Almenara, J. Página 22 de 23 
Rodríguez-Gallego, M. R., López-Martínez, A. y Navarro-Montaño, M. J. (2019). Longitudinal Study on Social Networks as a Didactic Method. Magis, Revista Internacional De Investigación En Educación, 12(24), 85-104. doi: 10.11144/Javeriana.m12-24.1ssn

Rodríguez-García, A. M., Raso-Sánchez, F. y Ruiz-Palmero, J. R. (2019). Competencia digital, educación superior y formación del profesorado: un estudio de metaanálisis en la Web of Science. Pixel-Bit. Revista de Medios y Educación, 54, 65-81. doi: 10.12795/pixelbit.2019.i54.04

Sahin, C. (2018). Social Media Addiction Scale - Student Form: The Reliability and Validity Study. TOJET: The Turkish Online Journal of Educational Technology, 17(1), 168-182.

Salim, P. y Luo, T. (2019). Factors contributing to student retention in online learning and recommended strategies for improvement: a systematic literature review. Journal of Information Technology Education: Research, 18, 19-57. doi: $10.28945 / 4182$

Sosa, A., Salinas, J. y Benito, B. de (2018). Las tecnologías emergentes en las actividades de aprendizaje al implementar un modelo de incorporación de tecnología en el aula. European Journal of Education Studies, 4(1), 155-173. doi: 10.5281/zenodo. 1158667

Tejada, E., Castaño, C. y Romero, A. (2019). Los hábitos de uso en las redes sociales de los preadolescentes. RIED. Revista Iberoamericana de Educación a Distancia, 22(2), 119-133. doi: 10.5944/ried.22.2.23245.

Torrego-González, A. y Gutiérrez-Martín, A. (2016). Ver y tuitear: reacciones de los jóvenes ante la representación mediática de la resistencia. Comunicar, 47, 9-17.

Valencia-Ortiz, R. y Castaño, C. (2019). Use and abuse of social media by adolescents: a study in Mexico. Pixel-Bit. Revista de Medios y Educación, 54, 7-28. doi: 10.12795/pixelbit.2019.i54.01

Yáñez-Luna, J.C. y Arias-Oliva, M. (2018). M-learning: aceptación tecnológica de dispositivos móviles en la formación online. Tecnología, Ciencia y Educación, 10, 13-34.

Yildirim, I. (2017). The effects of gamification-based teaching practices on student achievement and students' attitudes toward lessons. Internet and Higher Education, 33, 86-92. doi: 10.1016/j.iheduc.2017.02.002

Zamora, E. (2018). El grado de incidencia y nivel de impacto del manejo de los recursos didácticos por parte de los docentes y estudiantes dentro del aula virtual: una aproximación empírica. 3C TIC: Cuadernos de desarrollo aplicados a las TIC, 7(1), 33-46. doi: 10.17993/3ctic.2018.59.33-46.

Percepciones de estudiantes y docentes del uso que los estudiantes hacen de Internet y su relación con la modalidad de estudio. Valencia-Ortiz, Garay, U. y Cabero-Almenara, J. Página 23 de 23 